\title{
HUBUNGAN KEPATUHAN DAN PENGETAHUAN TENTANG APD DENGAN SAFETY TALK DI UNIT MAINTENANCE PERUSAHAAN SEMEN
}

\author{
Fajar Gumelar ${ }^{1}$, Denny Ardyanto ${ }^{2}$ \\ ${ }^{1}$ Program Studi S1 Kesehatan Masyarakat, Fakultas Kesehatan Masyarakat, Universitas Airlangga \\ ${ }^{2}$ Departemen Kesehatan dan Keselamatan Kerja, Fakultas Kesehatan Masyarakat, Universitas \\ Airlangga \\ fajargum10@gmail.com
}

\begin{abstract}
The level of achievement of the implementation of OHS at the cement plant in Indonesia is still very low. OHS effort to apply one of which is the implementation of the safety talk. Providing material survived behavior is expected to make workers subservient to the use of PPE and add to the knowledge workers of PPE. This study is observational and cross-sectional study design was used. Determination of the number of samples using simple random sampling method and obtained a sample of 67 workers. Data collected by interview using a questionnaire. The independent variables in this study is the safety talk while the dependent variable is compliance with PPE use and the level of knowledge of PPE. Program rating safety talk given by the company including the effective category (85.1\%). Compliance use of PPE included a positive category (56.7\%) and level of knowledge of PPE with good category (89.6\%). Statistical test using Pearson chi square and the results showed an association between safety talk with compliance $(p=0.001)$ and the correlation between safety talk with the knowledge of PPE $(p=0.000)$. The conclusion from this study is a relationship between compliance safety talk with the use of PPE and safety talk there is a relationship between the level of knowledge about APD. Advice can be given is the company expected to continue to improve adherence and knowledge of APD workers by providing a more effective safety talk.
\end{abstract}

Keywords: PPE, knowledge, compliance, safety talk, cement plant.

\begin{abstract}
ABSTRAK
Tingkat pencapaian penerapan K3 di pabrik semen di Indonesia masih sangat rendah. Upaya penerapan K3 salah satunya adalah dengan pelaksanaan safety talk. Pemberian materi perilaku selamat diharapkan dapat membuat pekerja menjadi patuh terhadap pemakaian APD dan menambah pengetahuan pekerja tentang APD. Penelitian ini merupakan penelitian observasional dan menggunakan rancangan penelitian cross sectional. Penentuan jumlah sampel menggunakan metode simple random sampling dan didapatkan sampel sebanyak 67 pekerja. Pengumpulan data dilakukan dengan wawancara menggunakan kuesioner. Variabel bebas pada penelitian ini adalah safety talk sedangkan variabel terikatnya adalah kepatuhan penggunaan APD dan tingkat pengetahuan tentang APD. Penilaian progam safety talk yang diberikan perusahaan termasuk kategori efektif $(85,1 \%)$. Kepatuhan penggunaan APD termasuk kategori positif (56,7\%) dan tingkat pengetahuan tentang APD dengan kategori baik $(89,6 \%)$. Uji statistik menggunakan pearson chi square dan menunjukan hasil terdapat hubungan antara safety talk dengan kepatuhan $(\mathrm{p}=0,001)$ dan terdapat hubungan antara safety talk dengan pengetahuan tentang APD $(\mathrm{p}=0,000)$. Kesimpulan dari penelitian ini adalah Terdapat hubungan antara safety talk dengan kepatuhan penggunaan APD dan terdapat hubungan antara safety talk dengan tingkat pengetahuan tentang APD. Saran yang dapat diberikan adalah perusahaan diharapkan dapat terus meningkatkan kepatuhan dan pengetahuan tentang APD pekerja dengan cara pemberian safety talk yang lebih efektif.
\end{abstract}

Kata kunci: APD, pengetahuan, kepatuhan, safety talk, pabrik semen 
Fajar, et al. Hubungan Kepatuhan dan Pengetahuan Tentang APD Dengan Safety Talk di Unit Maintenance Perusahaan Semen

\section{PENDAHULUAN}

Perkembangan industri di Indonesia saat ini berkembang begitu pesat, hal ini terlihat dari banyaknya perusahaan yang beroperasi di Indonesia. Menurut BPS RI (2012) tercatat sebanyak 23.257 perusahaan dari berbagai macam bidang beroperasi di Indonesia, meskipun demikian, tingkat pencapaian penerapan Keselamatan dan Kesehatan Kerja (K3) perusahaan di Indonesia masih sangat rendah. Menurut International Labour Organization (ILO) dari 15.017 perusahaan hanya $317(2 \%)$ perusahaan yang sudah menerapkan Keselamatan dan Kesehatan Kerja (K3) dengan baik, sedangkan sisanya 14.700 (98\%) perusahaan belum menerapkan Keselamatan dan Kesehatan Kerja (K3) secara baik. Data tersebut tentunya dapat me njadi tolak ukur pencapaian kinerja Keselamatan dan Kesehatan Kerja (K3) di Indonesia (Tarwaka, 2008).

Berbagai cara dilakukan perusahaan sebagai upaya penerapan Keselamatan dan Kesehatan Kerja (K3), salah satunya adalah dengan menerapkan perilaku K3 pada pekerja melalui enabling factor (faktor pemungkin) yaitu dengan penerapan safety talk di perusahaan. Safety talk termasuk dalam komunikasi Keselamatan dan Kesehatan Kerja (K3) antara manusia dengan manusia secara langsung, safety talk juga termasuk dalam jenis komunikasi kelompok dan banyak dilakukan melalui kontak individu yang bisa membentuk perilaku sesorang (Ramli, 2013). Adanya komunikasi tersebut bertujuan agar pekerja mendapatkan pengetahuan yang lebih banyak serta dapat meningkatkan kesadaran untuk menerapkan perilaku unsafe act menjadi safe act. Menurut Nasrullah (2014) penelitiannya mengemukakan bahwa pekerja yang mendapatkan safety talk yang baik akan memiliki pengetahuan dan attitude safe behavior yang lebih baik. Meskipun safety talk terbukti dapat mempengaruhi pengetahuan dan perilaku aman pekerja, pada kenyataannya masih saja dijumpai unsafe act pada pekerja. Tindakan tidak aman pekerja diantaranya adalah kurang patuhnya pekerja terhadap pemakaian Alat Pelindung Diri (APD) pada saat bekerja.

Penggunaan Alat Pelindung Diri (APD) diatur dalam UU no 1 tahun 1970 pasal 14 yang menyebutkan bahwa pengurus wajib menyediakan secara percuma, semua Alat
JPH RECODE Maret 2018; 1 (2) : 155-165 http://e-journal.unair.ac.id/JPHRECODE

Pelindung Diri yang diwajibkan pada tenaga kerja yang berada dibawah pimpinannya dan menyediakan bagi setiap orang lain yang memasuki tempat kerja tersebut, disertai dengan petunjuk yang diperlukan menurut petunjuk pegawai pengawas atau ahli keselamatan kerja. Meskipun tertulis pada UU no 1 tahun 1970 pasal 14 yang menghimbau agar para pekerja menggunakan Alat Pelindung Diri (APD) saat memasuki tempat kerja, pada kenyataanya masih banyak tenaga kerja yang tidak menggunakan Alat Pelindung Diri (APD) ketika bekerja (Departemen Hukum dan Perundang-Undangan, 1970). Menurut Sari (2014) Penelitian di Petrokimia Gresik mengemukakan bahwa $20,7 \%$ tenaga kerja berperilaku kadang tidak menggunakan Alat Pelindung Diri (APD) ketika bekerja.

Menurut UU no 1 tahun 1970 pasal 15 ayat 2 menyatakan bahwa tenaga kerja yang melanggar peraturan tentang keselamatan kerja akan mendapatkan ancaman pidana atas pelanggaran peraturannya dengan hukuman kurungan paling lama 3 (tiga) bulan dan denda paling besar Rp. 100.000,- (seratus ribu rupiah) (Departemen Hukum dan PerundangUndangan, 1970). Kemudian, Menurut UU no 13 tahun 2003 pasal 35 ayat 3 menyatakan bahwa pemberi kerja dalam memperkerjakan tenaga kerja wajib memberikan perlindungan yang mencakup kesejahteraan, keselamatan dan kesehatan baik mental maupun fisik tenaga kerja (Presiden Republik Indonesia, 2003).

Perilaku pekerja tidak akan terbentuk begitu saja, perilaku merupakan suatu hal yang sangat kompleks. Menurut teori Bloom dalam Notoatmodjo (2010), perilaku dibagi menjadi beberapa kategori yang terdiri dari kognitif, afektif, dan psikomotor atau dalam bentuk yang lebih operasional dapat diukur dengan knowledge (pengetahuan), attitude (sikap) dan practice (tindakan), dimana tiga hal tersebut mempengaruhi kepatuhan pekerja saat bekerja. Salah satu pengaruh dalam perilaku adalah pengetahuan yang merupakan domain penting untuk terbentuknya tindakan seseorang. Pengetahuan diperlukan sebagai dukungan dalam menumbuhkan rasa percaya diri maupun sikap dan perilaku setiap hari, sehingga dapat dikatakan bahwa pengetahuan merupakan fakta yang mendukung perilaku seseorang (Notoatmodjo, 2010). Meskipun demikian kenyataannya masih banyak pekerja yang mempunyai pengetahuan baik tetapi 
Fajar, et al. Hubungan Kepatuhan dan Pengetahuan Tentang APD Dengan Safety Talk di Unit Maintenance Perusahaan Semen

berperilaku kurang. Menurut Putra (2012) dalam penelitiannya menyatakan bahwa dari 97 orang responden yang memiliki pengetahuan baik dan berperilaku kurang sebanyak 45 orang $(46,4 \%)$.

Kepatuhan pekerja mengambil andil yang cukup besar dalam kesuksesan progam Keselamatan dan Kesehatan Kerja (K3) termasuk penggunaan Alat Pelindung Diri (APD). Menurut Feldman (2011) kepatuhan merupakan suatu sikap dan tindakan yang dilakukan seorang tenaga kerja karena stimulus tertentu. Stimulus yang menyebabkan kepatuhan tersebut dapat berupa permintaan, peraturan, perintah maupun paksaan yang akhirnya menimbulkan perilaku patuh untuk mengikuti stimulus. Meskipun himbauan dari perusahaan agar pekerja selalu patuh terhadap penggunaan Alat Pelindung Diri (APD) sudah diterapkan, masih saja didapatkan pekerja yang tidak patuh dalam menggunakan Alat Pelindung Diri. Menurut Joyo (2014) menyebutkan bahwa penelitian di PT Djitoe Indonesia Tabacco menunjukkan ada pengaruh pemberian penyuluhan $\mathrm{K} 3$ dengan tingkat kepatuhan pekerja dalam menggunakan APD yaitu sebelum penyuluhan diketahui kepatuhan pekerja dengan kategori rendah ada 10 orang $(45,45 \%)$ dan tinggi ada 12 orang $(54,55 \%)$ dan kepatuhan sesudah penyuluhan dengan kategori rendah ada 1 orang $(4,55 \%)$ dan tinggi ada 21 orang $(95,45 \%)$. Hal ini berarti menunjukkan bahwa perlu adanya penelitian lebih lanjut terkait penerapan safety talk terhadap pengetahuan serta kepatuhan pekerja pada penggunaan Alat Pelindung Diri (APD) di tempat kerja.

PT Holcim Indonesia Tbk terkenal sebagai pelopor dan inovator yang beroperasi di sektor industri semen yang tercatat sebagai sektor yang tumbuh pesat seiring pertumbuhan pasar perumahan, bangunan umum dan infrastruktur. Perusahaan ini pertama kali berdiri pada tahun 1971 dan bernama PT Semen Cibinong, perusahaan pertama yang sahamnya tercatat di Bursa Efek Jakarta pada tahun 1977 dan berganti nama menjadi PT Holcim Indonesia Tbk pada tahun 2006.

PT Holcim Indonesia Tbk mengoperasikan tiga pabrik semen masingmasing di Narogong, Jawa Barat, di Cilacap, Jawa Tengah, di Tuban, Jawa Timur dan fasilitas penggilingan semen di Ciwandan,
JPH RECODE Maret 2018; 1 (2) : 155-165 http://e-journal.unair.ac.id/JPHRECODE

Banten dengan total kapasitas gabungan per tahun 11 juta ton semen.

Perusahaan ini menghasilkan sebuah produk semen dengan cara mengolah batu kapur, tanah liat, pasir silica, pasir besi dan gypsum menjadi sebuah semen yang berkualitas yang digunakan masyarakat untuk mendukung pertumbuhan pasar perumahan, bangunan umum dan infrastruktur. Pengolahan pembuatan semen yang berkualitas dalam perusahaan ini membutuhkan peralatan yang canggih agar proses produksi bisa berjalan dengan baik oleh karena itu penggunaan mesin dan berbagai macam alat berat tidak dapat terhindarkan. Berbagai macam karakter tenaga kerja juga dapat menciptakan suatu kondisi yang memungkinkan untuk terjadinya kecelakaan kerja. Perlindungan terhadap tenaga kerja sangat diperlukan agar tercipta suasana yang aman, nyaman serta sehat bagi para tenaga kerja.

PT Holcim Indonesia Tbk telah menerapkan berbagai progam tentang Keselamatan dan Kesehatan Kerja (K3) diantaranya safety talk setiap pagi sebelum pekerja melakukan semua pekerjaanya. Dengan adanya safety talk perusahaan berharap pekerja dapat memiliki wawasan pengetahuan yang luas tentang Keselamatan dan Kesehatan Kerja (K3) terutama kepatuhan dalam menggunakan Alat Pelindung Diri (APD).

Meskipun penerapan progam safety talk sudah diterapkan diperusahaan, tetapi kenyataan dilapangan masih banyak ditemukan keteledoran karyawan dalam menggunakan peralatan kerja dan sering kali mengabaikan penggunaan Alat Pelindung Diri (APD) yang telah disediakan. Berdasarkan dari data observasi langsung selama kurang lebih satu bulan di perusahaan didapatkan dalam satu minggu kurang lebih terdapat 10 pekerja yang melakukan pelanggaran Keselamatan dan Kesehatan Kerja (K3) beberapa diantaranya tidak patuh dalam penggunaan Alat Pelindung Diri (APD) alasan para pekerja yang tidak memakai Alat Pelindung Diri (APD) pada saat bekerja adalah karena pekerja merasa tidak nyaman menggunakan Alat Pelindung Diri (APD) dan sebagian mengaku lupa. Berdasarkan hal tersebut, perlu dilakukan penelitian untuk mengetahui hubungan antara safety talk dengan tingkat pengetahuan dan 
Fajar, et al. Hubungan Kepatuhan dan Pengetahuan Tentang APD Dengan Safety Talk di Unit Maintenance Perusahaan Semen

kepatuhan penggunaan Alat Pelindung Diri (APD) Di PT Holcim Indonesia Tbk.

\section{METODE}

Penelitian ini dari segi pengambilan data termasuk penelitian observasional. Berdasarkan segi tempat merupakan penelitian lapangan karena pengambilan data dilakukan langsung di lapangan. Apabila ditinjau dari segi waktu, penelitian ini termasuk penelitian Cross sectional yaitu penelitian yang bertujuan untuk menganalisis hubungan variabel bebas dan variabel tergantung dan dilakukan dengan cara pengukuran atau pengamatan pada saat yang bersamaan atau sekali waktu.

Populasi dalam penelitian ini adalah semua tenaga kerja tetap yang tercatat di Unit Maintenance PT Holcim Indonesia Tbk sebesar 81 orang. Sampel penelitian ini adalah sebagian dari tenaga kerja di unit maintenance PT. Holcim Indonesia Tbk Indonesia Cara pengambilan sampel dalam penelitian ini dihitung dengan menggunakan rumus (Lemeshow, 1991) dengan rumus sebagai berikut:

$$
n=\frac{\mathrm{Z}^{2} 1-\alpha / 2 P(1-p) N}{\mathrm{~d}^{2}(\mathrm{~N}-1)+Z^{2} 1-\alpha / 2 P(1-p)}
$$

\section{Keterangan:}

$\mathrm{N}=$ Jumlah populasi

Z1- $\alpha / 2=$ Derajat ketetapan yang dikehendaki $0,05(\mathrm{Z}=1,96)$

$\mathrm{n}=$ Besar sampel

$\mathrm{p}=$ Proposi yang dikehendaki $(0,5)$

$\alpha=$ Derajat kepercayaan $(0,05)$

$\mathrm{d}=$ limit dari eror/ presisi absolut 0,05

Jumlah seluruh tenaga kerja kontrak maupun tenaga kerja tetap di Unit Maintenance PT Holcim Indonesia Tbk sebesar 81 orang, maka besar sampel:

$$
\begin{aligned}
& n=\frac{\mathrm{Z}^{2} 1-\alpha / 2 P(1-P) N}{\mathrm{~d}^{2}(\mathrm{~N}-1)+Z^{2} 1-\alpha / 2 P(1-P)} \\
& n=\frac{1,96^{2} \times 0,5(1-0,5) 81}{0,05^{2}(81-1)+1,96^{2} \times 0,5 \times 0,5} \\
& n=\frac{77,79}{1,16} \\
& n=67,06 \approx 67 \text { orang }
\end{aligned}
$$

JPH RECODE Maret 2018; 1 (2) : 155-165 http://e-journal.unair.ac.id/JPHRECODE

Jadi jumlah sampel yang digunakan dalam penelitian adalah sebesar 67 orang.

Cara menentukan sampel penelitian adalah menggunakan teknik Simple Random Sampling. Teknik simple random sampling dilakukan dengan cara menyusun daftar nama tenaga kerja yang menjadi populasi penelitian, dan memberi nomor urut pada daftar nama tenaga kerja dan mengundi nomor urut daftar nama tenaga kerja tersebut secara acak. Nomor undian tenaga kerja yang muncul pada undian secara acak akan dijadikan sampel penelitian. Pengundian ini bertujuan agar setiap orang dalam populasi mempunyai kesempatan yang sama untuk terpilih menjadi sampel secara acak.

Penelitian dilakukan di PT Holcim Indonesia Tbk, yang merupakan perusahaan produksi semen yang sebelumnya belum pernah dilakukan penelitian seperti ini. Penelitian dilakukan mulai bulan Maret 2015 hingga Januari 2016. Pengambilan data dilaksanakan pada bulan Oktober hingga November 2015.

Variabel penelitian dalam penelitian ini terdiri dari variable bebas dan variable tergantung, variable bebas dalam penelitian ini adalah safety talk sedangkan variable tergantung meliputi kepatuhan penggunaan APD dan pengetahuan tentang APD.

Umur yang dimaksud dalam penelitian ini adalah merupakan lama hidup pekerja sejak pekerja tersebut lahir sampai pada saat dilakukan penelitian ini. Penelitian ini membagi kelompok umur menjadi 4 kategori, yaitu $<20$ tahun, 20 tahun - 30 tahun, 31 tahun -40 tahun, dan $>40$ tahun.

Tingkat pendidikan yang dimaksud dalam penelitian ini adalah jenjang pendidikan formal terakhir yang ditempuh oleh responden sampai pada saat penelitian ini berlangsung. Penelitian ini membagi kelompok umur menjadi 4 kategori, yaitu SMA, D3, S1 dan S2.

Safety talk menurut Tarwaka (2015) merupakan pembacaan pesan-pesan singkat K3 yang dilaksanakan pada setiap hari sebelum para pekerja memulai pekerjaannya. Kriteria safety talk dapat diketahui dengan menggunakan 5 butir pertanyaan yang terkait pemberian safety talk di perusahaan. Dengan setiap item bernilai maksimal 4 dan minimal 1 . Sehingga dapat diperoleh skor tertinggi 20 dan terendah 4 . 
Fajar, et al. Hubungan Kepatuhan dan Pengetahuan Tentang APD Dengan Safety Talk di Unit Maintenance Perusahaan Semen

Safety talk dalam penelitian ini dikelompokkan menjadi 2 kategori, yaitu efektif dan kurang efektif. Dengan klasifikasi skor efektif jika skor 12-20 dan kurang efektif jika skor $<12$.

Kepatuhan menurut Ramdayana (2009) merupakan sebuah perubahan tindakan yang bersifat sementara dan memiliki kecenderungan kembali kepada pandangan atau perilaku semula jika pengawasan lemah. Kriteria Kepatuhan dapat diketahui dengan menggunakan 20 butir pertanyaan mengenai kepatuhan responden dalam menggunakan APD di Unit Maintenance. Kriteria jawaban diantaranya sangat tidak setuju (STS), tidak setuju (TS), netral (N), setuju (S) dan sangat setuju (SS). Masing-masing item diberi bobot nilai berdasarkan pernyataan favorable atau unfavorable. Pada pernyataan favorable $(\mathrm{F})$, diberikan penilaian 5 pada jawaban sangat setuju (SS), nilai 4 pada jawaban setuju (S), nilai 3 diberikan pada jawaban yang netral, nilai 2 diberikan pada jawaban tidak setuju (TS), dan nilai 1 diberikan untuk jawaban sangat tidak setuju (STS). Sebaliknya pada pernyataan unfavorable (UF), diberikan penilaian 1 pada jawaban sangat setuju (SS), nilai 2 pada jawaban setuju (S), nilai 3 diberikan pada jawaban netral, nilai 4 diberikan pada jawaban yang tidak setuju (TS), dan nilai 5 diberikan untuk jawaban sangat tidak setuju (STS). Setelah didapatkan skor dari setiap pertanyaan kemudian dimasukan rumus Setiadi (2007) yaitu:

$\mathrm{T}=50+10\left[\frac{X-\bar{X}}{s}\right]$

Keterangan:

$\mathrm{X}=$ skor responden pada skala sikap yang hendak diubah menjadi skor $\mathrm{T}$

$\bar{X}=$ mean skor kelompok

$\mathrm{S}=$ deviasi standar skor kelompok.

Kepatuhan dalam penelitian ini dikelompokkan menjadi 2 kategori, yaitu positif dan negatif. Dengan klasifikasi positif jika skor $\mathrm{T} \geq$ mean skor $\mathrm{T}$ dan negatif jika skor $\mathrm{T}<$ mean skor $\mathrm{T}$.

Pengetahuan menurut Notoatmodjo (2010) merupakan hasil dari kata "Tahu" yang artinya hal ini terjadi jika seseorang melakukan penginderaan terhadap suatu objek tertentu dan penginderaan tersebut terjadi melalui panca
JPH RECODE Maret 2018; 1 (2) : 155-165 http://e-journal.unair.ac.id/JPHRECODE

indera manusia yaitu mata, telinga, hidung, mulut dan kulit. Sebagian besar pengetahuan manusia diperoleh melalui pendidikan, pengalaman orang lain, media masa serta lingkungan. Kriteria pengetahuan diketahui dengan menggunakan 10 butir pertanyaan mengenai pengetahuan responden tentang APD di Unit Maintenance. Setiap pertanyaan dengan jawaban yang benar mempunyai skor 1 dan tiap pertanyaan dengan jawaban yang salah tidak mendapat skor. Pengetahuan dalam penelitian ini dikelompokkan menjadi 2 kategori, yaitu baik dan kurang. Dengan klasifikasi baik jika skor 8-10 dan kurang jika skor $<8$.

Data yang diperoleh selanjutnya ditampilkan dalam bentuk narasi, tabel distribusi frekuensi dan krostabulasi menggunakan uji korelasi, kemudian dihitung nilai odd ratio untuk mengetahui hubungan antara safety talk dengan kepatuhan dan pengetahuan tentang APD. Setelah data dianalisis, langkah selanjutnya adalah penarikan kesimpulan.

\section{HASIL}

Responden pada penelitian ini sebanyak 67 orang pekerja di Unit Maintenance PT. Holcim Indonesia Tbk. Pekerja paling muda dalam penelitian ini adalah berusia 22 tahun, sedangkan pekerja paling tua berusia 46 tahun. Usia ini menurut Undang-undang Nomor 13 Tahun 2003 tentang Ketenagakerjaan merupakan usia produktif yang memang diperbolehkan untuk bekerja (Presiden Republik Indonesia, 2003)

Frekuensi usia paling banyak yang ada di Unit Maintenance PT. Holcim Indonesia Tbk ada pada rentang 31 tahun sampai 40 tahun dimana usia tersebut sudah termasuk pada usia matang yang tentunya sarat akan pengalaman. Pengalaman pribadi juga dapat digunakan sebagai upaya memperoleh pengetahuan dengan cara mengulang kembali pengalaman yang pernah diperoleh dalam memecahkan permasalahan yang dihadapi masa lalu.

Tingkat pendidikan responden sebagian besar adalah S1. Hal tersebut menunjukan sebagian besar responden sudah memiliki tingkat pendidikan yang tinggi dimana dengan tingkat pendidikan yang tinggi tersebut diharapkan resonden dapat lebih baik pula dalam menerima berbagai informasi K3 
Fajar, et al. Hubungan Kepatuhan dan Pengetahuan Tentang APD Dengan Safety Talk di Unit Maintenance Perusahaan Semen

tentang APD di perusahaan. Pendidikan merupakan proses menumbuh kembangkan seluruh kemampuan dan perilaku manusia melalui pengetahuan, sehingga dalam pendidikan perlu dipertimbangkan umur (proses perkembangan klien) dan hubungan dengan proses belajar.

Safety Talk diberikan sebelum pekerjaan di Unit Maintenance PT Holcim Indonesia di
JPH RECODE Maret 2018; 1 (2) : 155-165 http://e-journal.unair.ac.id/JPHRECODE

dimulai, kegiatan safety talk dipimpin oleh orang yang bertanggung jawab (Supervisor). Penelitian terhadap pekerja yang mengikuti Safety Talk digunakan alat bantu berupa kuesioner dan dibagi menjadi dua kategori yaitu Efektif dan Kurang Efektif. Berikut akan dipaparkan distribusi frekuensi penilaian Safety Talk pada tabel 1 di berikut ini:

Tabel 1. Distribusi frekuensi Safety Talk di Unit Maintenance PT. Holcim Indonesia Tbk tahun 2015

\begin{tabular}{cccc}
\hline Variabel Penelitian & Kategori & n. & \% \\
\hline Safety talk & Efektif & 57 & 85,1 \\
& Kurang efektif & 10 & 14,9 \\
& & & \\
\hline Total & $\mathbf{6 7}$ & $\mathbf{1 0 0}$ \\
\hline
\end{tabular}

Berdasarkan tabel 1 dapat dinyatakan bahwa hampir seluruhnya responden mengikuti Safety Talk di Unit Maintenance PT Holcim Indonesia Tbk secara efektif. Hal ini menunjukan bahwa perusahaan telah melaksanakan kegiatan safety talk di unit maintenance dengan baik dan diharapkan dapat menambah pengetahuan pekerja tentang K3 terutama tentang APD dan merubah perilaku patuh pekerja agar menjadi lebih baik lagi.

Tabel 2. Distribusi frekuensi Kepatuhan Responden dalam penggunaan Alat Pelindung Diri di Unit Maintenance PT. Holcim Indonesia Tbk tahun 2015

\begin{tabular}{cccc}
\hline Variabel Penelitian & Kategori & n. & \% \\
\hline Kepatuhan & Positif & 38 & 56,7 \\
& Negatif & 29 & 43,3 \\
\hline Total & & $\mathbf{6 7}$ & $\mathbf{1 0 0}$ \\
\hline
\end{tabular}

Berdasarkan tabel 2 dapat dilihat bahwa lebih dari setengah responden memiliki kepatuhan yang positif tentang penggunaan Alat Pelindung Diri (APD) di Unit Maintenace PT Holcim Indonesia. Hal ini menunjukan bahwa lebih dari setengah pekerja memiliki perilaku kepatuhan yang positif tetapi masih banyak yang mempunyai perilaku kepatuhan yang negatif hal ini menunjukan bahwa hampir seluruh pekerja yang memilik pengetahuan baik tidak selalu didukung dengan kepatuhan yang baik.

Hasil penilaian pengetahuan responden tentang Alat Pelindung Diri (APD) didapat dari hasil kuesioner yang telah di isi oleh responden. Responden diminta untuk menjawab 10 pertanyaan yang terkait dengan
Kepatuhan merupakan suatu sikap dan tindakan yang dilakukan pekerja unit maintenance terhadap penggunaan APD. Hasil penilaian responden tentang kepatuhan penggunaan APD dilihat dari hasil kuesioner yang diisi oleh responden. Didapatkan hasil distribusi frekuensi kepatuhan penggunaan Alat Pelindung Diri di Unit Maintenance PT Holcim Indonesia Tbk dapat dilihat di tabel 2 berikut ini: pengertian Alat Pelindung Diri, peraturan tentang Alat Pelindung Diri, dan contoh Alat Pelindung diri. Distribusi frekuensi tingkat pengetahuan tentang Alat Pelindung Diri di Unit Maintenance PT Holcim Indonesia Tbk dapat dilihat di tabel 3 berikut: 
Tabel 3. Distribusi frekuensi Tingkat Pengetahuan Responden tentang Alat Pelindung Diri di Unit Maintenance PT. Holcim Indonesia Tbk tahun 2015

\begin{tabular}{cccc}
\hline Variabel Penelitian & Kategori & n. & \% \\
\hline Pengetahuan & Baik & 60 & 89,6 \\
& Kurang & 7 & 10,4 \\
\hline Total & & $\mathbf{6 7}$ & $\mathbf{1 0 0}$ \\
\hline
\end{tabular}

Berdasarkan tabel 3 dapat dilihat hampir semua responden memiliki pengetahuan yang baik. Hal ini menunjukan bahwa pekerja di unit maintenance sudah mempunyai pemahaman yang baik mengenai APD. Setelah mengetahui capaian program safety talk yang diterima pekerja unit maintenance PT Holcim Indonesia Tbk selanjutnya dihubungan dengan kepatuhan penggunaan APD pekerja untuk mengetahui adakah hubungan pada kedua variabel tersebut. Data tabulasi silang antara Safety Talk dan kepatuhan penggunaan APD pekerja bisa dilihat di tabel 4.

Berdasarkan tabel 4 dapat dilihat yang terbanyak yaitu pekerja yang mengikuti Safety Talk secara efektif dengan tingkat pengetahuan Tabel 4. Hubungan antara Safety Talk dengan Kepatuhan Penggunaan APD tahun 2015

\begin{tabular}{|c|c|c|c|c|c|c|c|}
\hline \multirow{3}{*}{$\begin{array}{l}\text { Variable } \\
\text { Penelitian }\end{array}$} & \multirow{3}{*}{ Kategori } & \multicolumn{4}{|c|}{ Kepatuhan } & \multirow{3}{*}{$P$} & \multirow{3}{*}{ Keterangan } \\
\hline & & \multirow{2}{*}{$\begin{array}{c}\text { Positif } \\
\text { N }\end{array}$} & \multicolumn{3}{|c|}{ Negatif } & & \\
\hline & & & $\%$ & $\mathbf{N}$ & $\%$ & & \\
\hline \multirow[t]{2}{*}{ Safety talk } & Efektif & 37 & 97,4 & 20 & 69 & 0,001 & Ada \\
\hline & Kurang efektif & 1 & 2,6 & 9 & 31 & & Hubungan \\
\hline
\end{tabular}

Tabel 5. Hubungan antara Safety Talk dengan Pengetahuan tentang APD tahun 2015

\begin{tabular}{|c|c|c|c|c|c|c|c|}
\hline \multirow{3}{*}{$\begin{array}{l}\text { Variable } \\
\text { Penelitian }\end{array}$} & \multirow{3}{*}{ Kategori } & \multicolumn{4}{|c|}{ Pengetahuan } & \multirow{3}{*}{$\boldsymbol{P}$} & \multirow{3}{*}{ Keterangan } \\
\hline & & \multirow{2}{*}{$\begin{array}{c}\text { Baik } \\
\mathbf{n}\end{array}$} & \multicolumn{3}{|c|}{ Kurang } & & \\
\hline & & & $\%$ & $\mathbf{N}$ & $\%$ & & \\
\hline \multirow[t]{2}{*}{ Safety talk } & Efektif & 56 & 93,3 & 1 & 14,3 & 0,000 & Ada \\
\hline & Kurang efektif & 4 & 6,7 & 6 & 85,7 & & Hubungan \\
\hline
\end{tabular}

$p=0,000(p<\alpha)$. Hal ini menunjukan bahwa terdapat hubungan antara safety talk dengan tingkat pengetahuan tentang APD.

\section{PEMBAHASAN}

\section{Safety Talk}

Berdasarkan Tabel 1 menunjukkan hampir seluruhnya responden mengikuti safety talk di unit Maintenance PT. Holcim Indonesia Tbk secara efektif. Safety talk yang efektif di unit Maintenance PT. Holcim Indonesia Tbk mengindikasikan bahwa penyampaian pesan keselamatan dan kesehatan kerja sudah jelas dan dipahami oleh sebagian besar pekerja. Safety talk diberikan sebelum pekerjaan di Unit Maintenance PT Holcim Indonesia di dimulai dan dipimpin oleh orang yang tentang APD yang baik lalu dilakukan uji statistik menggunakan pearson chi-square diperoleh hasil $p=0,001 \quad(p<\alpha)$. Hal ini menunjukan bahwa terdapat hubungan antara safety talk dengan tingkat pengetahuan tentang APD. Selanjutnya dihubungkan antara safety talk dengan tingkat pengetahuan tentang APD pekerja. Data tabulasi silang antara Safety Talk dan pengetahuan tentang APD pekerja tertera di tabel 5. Berdasarkan tabel 5 dapat dilihat yang terbanyak adalah pekerja yang mengikuti Safety Talk secara efektif dengan tingkat pengetahuan tentang APD yang baik lalu dilakukan uji statistic menggunakan pearson chi-square dan diperoleh hasil: 
Fajar, et al. Hubungan Kepatuhan dan Pengetahuan Tentang APD Dengan Safety Talk di Unit Maintenance Perusahaan Semen

keselamatan untuk peralatan, bahan, dan prosedur yang mereka gunakan setiap hari untuk pekerjaan tertentu.

Menurut Tarwaka (2015) Safety talk termasuk upaya pengendalian risiko yang ada dalam pengendalian administrasi. Safety talk merupakan pembacaan pesan-pesan singkat K3 yang dilaksanakan pada setiap hari sebelum para pekerja memulai pekerjaannya. Tujuan diadakannya program Safety talk ini adalah agar para pekerja termotivasi dalam bekerja dan lebih berhati-hati dalam melakukan pekerjaannya. Safety talk berisi tentang pesan $\mathrm{K} 3$, prosedur kerja yang aman, anjuran menggunakan APD di tempat kerja serta himbauan agar pekerja selalu berhati- hati dengan keadaan lingkungan yang berpotensi berbahaya.

Hal tersebut sesuai dengan pendapat Tarwaka (2015) yang menyatakan bahwa Safety talk adalah pembacaan pesan singkat K3 yang dilaksanakan pada setiap hari sebelum tenaga kerja memulai pekerjaannya. Tujuan diadakannya program Safety talk adalah agar para tenaga kerja termotivasi dalam bekerja dan lebih waspada dalam melakukan pekerjaannya. Progam safety talk berisi tentang pesan $\mathrm{K} 3$, prosedur kerja yang aman, anjuran menggunakan APD di tempat kerja serta himbauan agar pekerja selalu waspada dengan keadaan lingkungan yang berpotensi berbahaya.

\section{Kepatuhan}

Berdasarkan Tabel 2 diketahui lebih dari separuhnya responden memiliki kepatuhan yang positif dalam penggunaan APD. Hal tersebut berarti pekerja di Unit Maintenance sebagian besar memiliki sikap serta tindakan yang taat dalam mematuhi peraturan yang berlaku di tempat kerja dan mempunyai kesadaran diri akan bahaya yang bisa terjadi jika pekerja tidak patuh terhadap penggunaan APD. Namun beberapa pekerja masih memiliki kepatuhan yang negatif dan mengaku sering lupa akan menggunakan APD, karena tidak menggunakan APD menurut mereka bukan termasuk masalah besar dan pekerja mengaku tidak nyaman dalam menggunakan APD saat bekerja.

Perusahaan telah menerapkan system reward dan punishment kepada tenaga kerja yang tidak patuh dan patuh terhadap peraturan
JPH RECODE Maret 2018; 1 (2) : 155-165 http://e-journal.unair.ac.id/JPHRECODE

perusahaan tetapi jumlah nominalnya tidak diketahui oleh tenaga kerja.

Menurut Carpenito (2000) patuh adalah sikap positif klien yang diaplikasikan dalam bentuk perubahan perilaku secara berarti sesuai tujuan. Menurut Ramdayana (2009) mengemukakan bahwa kepatuhan seseorang merupakan perubahan tindakan yang sementara waktu dan memiliki kecenderungan kembali ke pandangan atau perilaku yang semula jika pengawasan lemah.

Menurut Sastrohadiwiryo (2005) bahwa kepatuhan seseorang dapat dipengaruhi oleh tingkat pendidikan orang tersebut, tingkat pendidikan berhubungan dengan tugas dan tanggung jawab seseorang. Semakin tinggi pendidikan seseorang maka semakin banyak informasi yang masuk, semakin banyak pula pengetahuan yang didapat.

Hal tersebut sesuai dengan pendapat Sinungan (1997) bahwa kepatuhan merupakan sebuah sikap yang ditunjukkan dalam bentuk perilaku seseorang, kelompok atau masyarakat yang berupa ketaatan terhadap peraturan atau ketentuan yang telah ditetapkan oleh pemerintah atau etik, norma dan kaidah yang berlaku dalam masyarakat untuk tujuan tertentu.

Hal tersebut sejalan dengan pendapat Feldman (2011) yang membedakan kepatuhan menjadi dua yaitu compliance dan obedience. Bila diterjemahkan ke dalam Bahasa Indonesia, baik compliance dan obedience memiliki arti yang sama yaitu kepatuhan, namun sebenarnya jika dimaknai compliance dan obedience memiliki beda makna. Compliance adalah bentuk kepatuhan yang menjelaskan bahwa tindakan seseorang yang bersedia melakukan suatu hal karena menyetujui sebuah permintaan dan bukan karena perintah atau paksaan dari atasan. Misalnya seorang tenaga kerja akhirnya menggunakan safety shoes setelah menyetujui bahwa safety shoes akan melindungi kaki dari kejatuhan benda berat. Obedience adalah perubahan sikap dan tindakan seseorang untuk mengikuti permintaan atau perintah orang lain tanpa mempedulikan persetujuan orang tersebut. Misalnya tenaga kerja menggunakan safety shoes jika supervisor memerintahkan tenaga kerja menggunakan safety shoes. 
Fajar, et al. Hubungan Kepatuhan dan Pengetahuan Tentang APD Dengan Safety Talk di Unit Maintenance Perusahaan Semen

\section{Pengetahuan}

Berdasarkan Tabel 3 diketahui hampir seluruhnya responden memiliki tingkat pengetahuan tentang APD yang baik. Pengetahuan pekerja tentang APD di unit maintenance PT. Holcim Indonesia Tbk dipengaruhi oleh beberapa faktor diantaranya umur, pendidikan, pengalaman orang lain, media massa maupun lingkungan. Pengetahuan merupakan domain yang sangat penting dalam pembentukan perilaku individu.

Berdasarkan hal tersebut perusahaan memberikan progam safety talk agar pekerja dapat memperoleh pengetahuan yang lebih baik. Hal tersebut sesuai dengan teori Hapsari (2013) bahwa peningkatan pengetahuan pekerja terhadap risiko dan bahaya kerja dapat dilakukan dengan penambahan media edukasi seperti pemasangan poster, pelatihan $\mathrm{K} 3$, safety briefing, dan lain sebagainya.

Menurut Notoatmodjo (2010) semakin tinggi umur seseorang, maka semakin bertambah pula ilmu atau pengetahuan yang dimiliki, karena pengetahuan seseorang diperoleh dari pengalaman sendiri maupun pengalaman yang diperoleh dari orang lain. Pendidikan merupakan proses menumbuh kembangkan seluruh kemampuan dan perilaku manusia melalui pengetahuan. Tingkat pendidikan juga merupakan salah satu faktor yang mempengaruhi persepsi seseorang atau lebih mudah menerima berbagai ide dan teknologi.

Hal tersebut sesuai dengan pernyataan Hurlock (2004) bahwa usia dewasa (18-40 tahun) merupakan masa dimana seseorang secara maksimal dapat mengingat dengan baik dan mempunyai pengalaman yang cukup sehingga dapat mencapai prestasi yang memuaskan dalam karirnya baik dari segi pendidikan maupun pekerjaan. Semakin tinggi pendidikan, hidup manusia akan semakin berkualitas karena pendidikan yang tinggi akan membuahkan pengetahuan yang baik dan akan menjadikan hidup semakin berkualitas.

\section{Hubungan antara safety talk dengan kepatuhan dalam penggunaan apd}

Berdasarkan Tabel 4 diketahui bahwa responden yang mengikuti safety talk secara efektif hampir seluruhnya memiliki kepatuhan yang positif dalam penggunaan APD. Setelah dianalisis menggunakan uji statistik pearson chi-square menunjukkan bahwa terdapat
JPH RECODE Maret 2018; 1 (2) : 155-165 http://e-journal.unair.ac.id/JPHRECODE

hubungan antara safety talk dengan kepatuhan penggunaan APD.

Hasil penelitian tersebut menunjukan kesesuaian dengan pernyataan Wadji (2013) dengan adanya safety talk diharapkan dapat merubah perilaku diri diantaranya adalah melaksanakan prosedur kerja yang benar. Semakin sering kita melakukan pekerjaan yang sama, kita menjadi terbiasa dan semakin menguasai pekerjaan. Namun hal tersebut dapat pula menjadikan kita terlena dengan kemampuan tersebut karena sudah terbiasa melakukan pekerjaan secara berulang terkadang menjadikan kita lalai, gegabah dan menganggap remeh prosedur kerja yang harus dilalui, yang akibatnya bisa berakibat fatal terhadap peralatan maupun manusianya. Apabila kita bekerja dengan mengikuti prosedur yang telah ditentukan, maka kita sudah terlindungi bila terjadi hal-hal yang tidak kita inginkan, karena persiapan, pemeriksaan dan pengesahan terhadap prosedur kerja selalu dalam kontrol sistem sehingga mampu meminimalkan dan mencegah terjadinya kecelakaan kerja.

Hasil penelitian ini didukung oleh penelitian Nasrullah (2014) terdapat hubungan antara safety talk dengan sikap dan tindakan safe behavior, yang berarti bahwa tenaga kerja yang mendapatkan safety talk dengan baik kemungkinan akan mempunyai sikap dan tindakan safe behavior yang baik.

Penelitian Kartika (2014) menyatakan bahwa pengetahuan memilliki hubungan yang signifikan terhadap kepatuhan pekerja dalam menggunakan APD di tempat kerja. Pekerja yang patuh menggunakan APD sebagian besar berpendidikan tinggi dan memili sikap yang baik terhadap kebijakan yang berlaku tentang APD di perusahaan.

\section{Hubungan antara safety talk dengan pengetahuan tentang apd}

Berdasarkan Tabel 5 diketahui bahwa responden yang megikuti safety talk di unit maintenance PT. Holcim Indonesia Tbk secara efektif hampir seluruhnya memiliki tingkat pengetahuan tentang APD yang baik. Setelah dianalisis menggunakan uji statistik pearson chi-square menunjukkan bahwa terdapat hubungan antara safety talk dengan pengetahuan tentang APD.

Hasil penelitian tersebut sesuai dengan pernyataan Wadji (2013) yang menyatakan 
Fajar, et al. Hubungan Kepatuhan dan Pengetahuan Tentang APD Dengan Safety Talk di Unit Maintenance Perusahaan Semen

adanya safety talk diharapkan dapat merubah pengetahuan kita salah satunya adalah mengetahui tentang peralatan safety atau alat pelindung diri (APD). Hal ini disebabkan karena setiap pekerja mempunyai tanggung jawab yang sama untuk bekerja dengan aman dan memperhatikan keselamatan sehingga pekerja mampu mengenali berbagai macam bahaya yang mungkin timbul di area kerja dan alat pelindung diri apa saja yang harus digunakan.

Hal tersebut sesuai dengan pernyataan Keller (2010) yang menyatakan bahwa safety talk tidak memerlukan waktu yang lama. Justru safety talk yang baik adalah safety talk yang singkat dan jelas. Keefektivitasan safety talk bergantung pada persiapan dan penilaian kondisi pekerjaan oleh supervisor. Perencanaan pekerjaan adalah bagian yang penting dari progam manajamen keselamatan.

Hasil penelitian ini didukung oleh penelitian Nasrullah (2014) terdapat hubungan antara safety talk dengan pengetahuan safe bahavior, yang berarti bahwa tenaga kerja yang mendapatkan safety talk dengan baik kemungkinan akan mempunyai pengetahuan safe behavior yang baik

\section{KESIMPULAN}

Kegiatan safety talk dilakukan setiap hari di unit maintenance PT Holcim Indonesia Tbk dan hampir seluruh responden mengikuti kegiatan safety talk di unit maintenance PT Holcim indonesia secara efektif. Lebih dari setengah responden di unit maintenance PT Holcim Indonesia Tbk memiliki kepatuhan yang postif dalam penggunaan APD. Hampir seluruh responden di unit maintenance PT Holcim Indonesia Tbk memiliki tingkat pengetahuan yang baik tentang APD. Pekerja yang mengikuti safety talk secara efektif di unit maintenance PT Holcim Indonesia Tbk akan memiliki kepatuhan penggunaan APD yang positif. Pekerja yang mengikuti safety talk secara efektif di unit maintenance PT Holcim Indonesia Tbk akan memiliki tingkat pengetahuan tentang APD yang baik.

\section{SARAN}

Disarankan perusahaan melakukan evaluasi pada waktu kegiatan safety talk berlangsung untuk mengetahui pengetahuan pekerja tentang materi yang disampaikan saat safety talk. Mensosialisasikan nilai nominal
JPH RECODE Maret 2018; 1 (2) : 155-165 http://e-journal.unair.ac.id/JPHRECODE

punishment kepada tenaga kerja agar tenaga kerja mengetahui berapa denda yang harus mereka bayar jika tidak patuh terhadap peraturan tentang APD yang telah diterapkan pada peraturan perusahaan untuk memberikan efek jera kepada tenaga kerja. Memberikan penghargaan kepada tenaga kerja yang patuh terhadap penggunaan APD dengan cara menempelkan nama tenaga kerja teladan dalam bentuk poster dan memberikan hadiah sesuai kemampuan perusahaan untuk memberikan rasa bangga terhadap tenaga kerja tersebut, sehingga tenaga kerja semakin antusias terhadap kepatuhan penggunaan APD.

\section{DAFTAR PUSTAKA}

BPS RI (2012) 'Statistik Indonesia 2012'.

Carpenito, L. 2000. Buku Diagnosa Keperawatan. Jakarta: EGC.

Departemen Hukum dan PerundangUndangan. 1970. Undang-Undang Nomor 1 Tahun 1970 Tentang Keselamatan Kerja, Presiden Indonesia.

Feldman, R. 2011. Understanding Psychology. McGraw-Hill.

Hurlock, E. 2004. Developmental Psychologi. Jakarta: Erlangga.

IHSA. 2007. Safety Talk. Diakses dari: www.csao.org/images/pfiles/119_v005.p df.

Joyo, T. 2014. Pengaruh Pemberian Penyuluhan K3 Terhadap Tingkat Kedisiplinan Pekerja Dalam Pemakaian Alat Perlindungan Diri (APD) Di PT. Djitoe Indonesia Tobacco. Skripsi, Universitas Muhammadiyah Surakarta.

Kartika, P. 2014. Analisis Faktor Yang Berhubungan Dengan Kepatuhan Menggunakan Alat Pelindung Diri (Studi Pada Unit Produksi Alumunium Sulfat PT. Liku Telaga Gresik. Skripsi, Universitas Airlangga, Surabaya.

Keller, K. 2010. Electrical safety code manual. Diakses dari: http://books.google.co.id/books?id=_R WGr21jytsC\&printsec $=$ frontcover\&hl $=\mathrm{i}$ $\mathrm{d} \&$ source $=$ gbs_ge_summary_r\&cad $=0 \#$ $\mathrm{v}=$ onepage $\& \mathrm{q} \& \mathrm{f}=\mathrm{f}$ alse.

Lemeshow, S., Hosmer, D.W., Klar, J \& Lwanga, S.K. 1991. Sample Size Determination In Health Studies. A Practical Manual. Geneva: World Health Organization (WHO), 1998. Role 
of the pharmacist in the health care system. Netherlands.

Nasrullah, M. 2014. Hubungan Antara Safety Briefing Dan Pengawasan K3 Terhadap Tingkat Safe Behavior. Skripis, Universitas Airlangga, Surabaya.

Notoatmodjo, S. 2010. Ilmu Perilaku Kesehatan. Cetakan Pertama. Jakarta: Rineka Cipta.

Presiden Republik Indonesia. 2003. UndangUndang No.13 Tahun 2003 tentang Ketenagakerjaan.

Putra, M. U. 2012. Hubungan Tingkat Pengetahuan Dan Sikap Dengan Perilaku Penggunaan Alat Pelindung Diri Pada Mahasiswa Profesi Fakultas Ilmu Keperawatan Universitas Indonesia. Skripsi, Universitas Indonesia, Depok.

Ramdayana. 2009. Faktor-Faktor Yang Berhubungan Dengan Tingkat Kepatuhan Perawat Terhadap Penggunaan Alat Pelindung Diri (APD) Di Ruang Rawat Inap RS. Marinir Cilandak Jakarta Selatan. Skripsi, Universitas Indonesia, Depok.

Ramli, S. 2013. SMART SAFETY: Panduan Penerapan SMK3 yang efektif. Jakarta: Dian Rakyat.

Sari, D. 2014. Analisis Faktor Yang Berhubungan Dengan Penggunaan APD Di Unit Produksi III PT. Petrokimia Gresik. Skripis, Universitas Airlangga, Surabaya.

Sastrohadiwiryo, B. 2005. Manajemen Tenaga Kerja Indonesia Pendekatan Administratif dan Operasional. Jakarta: PT Bumi Aksara.

Setiadi. 2007. Anatomi dan Fisiologi Manusia. Yogyakarta: Graha Ilmu.

Sinungan, M. 1997. Produktivitas Apa dan Bagaimana. Jakarta: Bumi Aksara.

Tarwaka. 2008. Keselamatan dan Kesehatan Kerja: Manajemen dan implementasi K3 di Tempat Kerja. Surakarta: Harapan Press.

Tarwaka. 2015. Keselamatan, Kesehatan Kerja dan Ergonomi (K3E) dalam Perspektif Bisnis. Surakarta: Harapan Press.

Wadji, F. 2013. Pentingnya Safety Talk Pada Proyek Konstruksi. Diakses dari: http://ekonomi.kompasiana.com/manaje men/2013/04/01/pentingnya-safety-talkpada-pekerjaan-konstruksi 546909.html. 